\title{
The Significance of Ontogeny and Habitus in Constructing Theories of Learning
}

\author{
Martin Bloomer, University of Exeter ${ }^{1}$ \\ Phil Hodkinson, University of Leeds \\ Stephen Billett, Griffith University
}

Bloomer, M, Hodkinson, P \&, Billett, S (2004) The Significance of Ontogeny and Habitus in Constructing Theories of Learning Studies in Continuing Education 26 (1) 19-43

\section{Correspondence:}

Phil Hodkinson (Prof.)

School of Continuing Education

University of Leeds

LEEDS, LS2 9JT

UK

Tel: (0) 1132333223

\section{Email: p.m.hodkinson@leeds.ac.uk}

\section{Abstract}

Much recent theorising about learning has focused on its socio-cultural nature, including the significance of history and the ontogeny of learners. This paper explores the relevance of such an approach to our understanding of the reasons why academics associate themselves with particular theoretical approaches to learning. The authors each present an autoethnographic account of the origins of their own theoretical orientations. This reveals the significance of ontogeny and habitus, which enable and constrain our academic work. The paper concludes by arguing that we need to understand academic research and theorising as partly personalised social practice, in ways that poses challenges for those who view research as an inherently rational and logical process.

\section{Introduction}

The literature on learning is and has always been one of competing theoretical and conceptual assumptions and positions. At different periods, differing theories have achieved some dominance, but none has ever established universal acceptance and support. Since the late 1980s, or thereabouts, theories of learning that emphasise its social and cultural character, often deriving from the work of Vygotsky, have attained some prominence. One of us, Billett, has been a contributor to that work. Central to this sort of theorising is the significance of the cultural contexts in which learning takes place and how individuals' thinking acting and, therefore, learning are shaped by these contexts. What is more, these contexts can only be understood through their evolution. The life histories or ontogeny of learners are a central dimension of this theorising, as they reflect the history of individuals' thinking and acting over time and in unique combinations of

${ }^{1}$ Tragically, Martin Bloomer died, of brain cancer, in November 2002. Billett and

Hodkinson completed this paper after his death, partly as a memorial to his work. 
engagement with social and cultural context that evolve over time. In this way, the interrelation between history and ontogeny seem central to understanding learning. In particular, although the contribution of human agency and identity or subjectivity are common to many theories of learning they are brought into tight focus by a consideration of relations between individuals' ontogenies and the transforming social practice they engage with. From a humanist perspective, agency is seen as the individual acting on the world and exercising a capacity to shape and forge a personal direction (Davies 2000). Subjectivities are generative of and fortified by this exercise. However, from a poststructural perspective, Davies (2000) proposes that human agency and, hence, subjectivity is contested and reciprocal. The individual is subject to the press of social and cultural practices, as well as exercising a capacity for independence and selffulfilment. So when considering theories that emphasise the cultural and social character of learning, an account of these relations and the centrality of subjectivity and agency set within social and cultural milieux comes to the forefront.

What has been given less attention, is the significance of culture and ontogeny and their relationships in the development of these theoretical perspectives on learning themselves. Yet, if the theories are creditable in relation to learning, then the same sorts of analysis can and should be applicable in the development of and affiliation with individuals' own theories of learning. For these are themselves particular, if rather specialised, exemplars of the learning process. This paper begins an exploration of this sparsely charted territory. Its focus is on the development of three individuals' preferences for particular explanations of learning - learning theories. It is proposed that these preferences can be understood through a consideration of life histories and their subjectivities that are a product of the agentic actions that constitute their ontogenies.

This project arose out of a meeting between the three authors at a conference in Australia, in 2000. Prior to that time, two of us, Bloomer and Hodkinson, had been working together for several years, examining the 'learning careers' of students in English further education. In carrying out that research, and especially when writing about it, an interesting partial separation in our thinking became apparent. For, whilst Bloomer consistently saw symbolic interactionism as the most useful theoretical bedrock, Hodkinson saw the thinking of Pierre Bourdieu as of ultimately greater significance. Over at least three years, we worked towards a closer common understanding, but this difference in emphasis remained. Therefore, there were more than just matters of rationality, evidence and logical argument at work here.

Hodkinson and Billett, on the other hand, had been broadly aware of each other's work for several years, but neither had devoted serious attention to the corpus of the other's output. What became apparent in the Australian meeting, as we listened to each other's papers in the conference and chatted in the bar, was that there was a significant overlap between the research interests and writing of all three of us. Central to this overlap was the issue of relations that Hodkinson and Bloomer refer to structure and agency from a sociological perspective, and Billett, from his psychological perspective as relations between individual ontogeny and social practice or, as Valsiner and van de Veer (2000) suggest, between the cognitive and social experience.

The conventional way forward, in this situation, would have been to explore in detail the strengths and weaknesses of our three differing positions, to search for areas of common understanding (there are many) and, ultimately, attempt to construct some new 
theorising, drawing upon the best of our over-lapping positions/traditions. Whilst not entirely ruling that sort of activity out, we chose a different approach, and this paper attempts to answer two different questions. Why do the three of us see very similar issues, problems and situations through different theoretical lenses? What are the implications of the answer to this first question, for our understanding of learning, and of the nature of theory in the construction of research?

Drawing on our shared interests in learning careers and/or ontogeny, we begin that process by each of us, separately, exploring the trajectories of our own thinking about learning, through retrospective and reflective narratives. There are some difficulties with this approach. The accounts are necessarily subjective and partial. There are things about our lives that we may not wish to tell each other, let alone share with other readers, some of whom will know us. Also, our analyses are written from a present that colours our thinking and understanding of our pasts. We are vulnerable to the well-known tendency to make our past experiences coherent, in ways that may have appeared nothing of the sort, as they actually developed. In this sense, the stories that follow may present an over-rationalised explanation, which readers need to recognise as at least partly posthoc. This is reinforced by our use of realist confessional tales, rather than, say, poetry or drama, or tales of fractured and contradictory experiences (See Sparkes, 2002, for a discussion of different approaches to academic writing). This was not a considered decision. We simply wrote the way we write, as practising academics. We found the focus on self-revelation challenging enough. To counter problems of post-hoc reconstruction, we have drawn upon external evidence, including some of our own former writings, where relevant. This, in turn, further drew us in to rational debate, and may have undervalued the social, embodied and emotional dimensions of our developing theoretical preferences. However, as none of us has kept a reflective journal throughout our professional lives, we had no other strategy to draw upon. As is so often the case with research, we have tried to do the best with the opportunities that were available to us.

. So these stories are not intended to examine fully the nature of our academic careers, or the relationships between our careers and other key parts of our lives, such as current family, community involvement, politics and leisure. Rather, each of us independently tried to understand why we felt about learning theory in the ways that we did. It was methodologically important not to pre-structure these stories, as to do so would have been to prejudge what we were expecting to find. This could only have been done by adopting an agreed theoretical stance at the outset - but we wanted to examine why we saw things differently, rather than draw closer together.

Similarly, we have not attempted to analyse either the ways in which our stances are similar, or the reasons for those similarities. In reflecting on ourstories, some hints about this appear, but they are only partial. Though structured differently, there are obvious similarities in these stories. For example, each of us returned to his schooldays. None of us talked explicitly about our current families. There are also significant differences: two of us talk about professional relationships, one does not. Readers may choose to speculate as to why this is the case. Our answer would be that these are the things that we each think influenced our current theoretical positions - no more, and no 
less. We lack the space to add a further reflective turn, and analyse for ourselves why our stories take the form that they do.

Some obvious issues of identity and position need to be made explicit. We are/were all successful white male academics. The stories are men's stories. Gender is important in the stories, but does not explain our theoretical differences, and so is not our main focus in this paper. Our academic success is significant in a different way. These are not the sorts of story that any of us could have written before we were fairly secure in our status and reputations. But that status in some ways increases the sense of personal risk, as some readers will know us or know of us. This may partly account for the absence of any detail about our current private lives, or of conflicts with academic colleagues.

\section{Stephen Billett's Story}

My recollections of secondary schooling in Lancashire (I failed my 11+, and therefore had to attend a secondary modern, rather than a grammar school) was of an often brutal environment, where students used brutal means to assert their status (e.g. violence and threats of violence), where teachers countered with brutal acts (e.g. corporal punishment, or threats of such punishment) and the bases of relations between peers was often quite summary (e.g. inclusion or exclusion from groups and distinctions). My preference was to work independently and be outside of the class clique. Much of this preference was based on a desire to set my own direction, rather than be a follower of that set by others. I also developed a strong distaste for bullying in its various forms, including the overt use of power. There was also a lack of ease and skill with the kinds of social interactions required to sustain relations and accept the group's norms that did not really interest me. I often questioned why individuals wanted to give up so much of themselves simply to be accepted by peers. This independence sometimes caused difficulties with peers and also teachers who from time to time took exception to my desire for independence. Well I remember, the senior English teacher clutching the knot of my tie and violently shaking my head for some expression of independence that he took as insolence.

Extending this independence, as a young man, I left my hometown and country and traveled largely unaccompanied for a number of years. This included an overland trip from Britain to Australia, then to live in Israel and travel down through parts of Africa. I then returned to Australia and established the group of friends who constitute my social life and also met a partner and her family that now constitutes much of my family life. In my work life, as a clothing technician I enjoyed a technical prowess that was the product of a college-based preparation, which was augmented by supportive work-based experiences. This prowess allowed me to contribute technically and in a way that few others in the workplaces were able. My preference was for technical work, rather than managerial roles that required competencies I didn't possess and the kinds of interactions that did not capture my interest. I always felt less comfortable in interactions with management or sales staff with their higher levels of social competence and faster and fancier footwork. Later, in my teaching work, the qualities of thorough preparation, which permitted an interactive approach to teaching students and strong technical knowledge were recognized as my strengths. However, in my teaching roles and other 
work, my preference for independence and autonomy has not always endeared me to colleagues and supervisors. So preferences that arose earlier in life directed me to engage in work in which I could enact independently of others and in ways that permit my energies to be engaged in new activities because I get bored easily, when not engaged in activities that capture my interest.

However, this simple interest-directed biography is complicated by other and contradictory concerns. From an early age, I recall a dread of being the centre of public attention. My lasting memory of primary school was being placed on a table by the teacher, to show all my classmates the jumper my mother had knitted. I can still recall tripping down stairs in a school assembly on being awarded a swimming medal (along with others), and hearing the derision of peers. I left the boy scouts largely to avoid my turn at reading a passage of the bible at the monthly Sunday church service, which caused me enormous anxiety. Also, much later, I cancelled my first ever conference paper when nerves and fear of public presentations become overwhelming. Curiously, when becoming a teacher, I clearly remember thinking that I could never become a teacher educator or a researcher because they both had to present publicly to informed audiences. This point complicates the issue of interests, subjectivities and preferences as I have and still perform both of these roles, yet highlights the kind of contested subjectivities that Davies (2000) seems to refer. So within my life direction there are complications and contestations between key goals (e.g. to work independently and with new ideas) and the need to overcome obstacles that stand in the way of those goals (e.g. self confidence, fear of ridicule). So here there are bases to consider the individual and the social as being at times antagonistic partners. Taking these ideas forward, it is timely to now turn to two directions for inquiry that illustrate how events in my personal history have shaped the course and focus of my research activities and preference for learning theories.

\section{Direction 1 - Workplace learning}

My interest in and research into workplace learning began in the early 1990s. At that time, I was employed in the state vocational education authority working with and encouraging enterprises (businesses) to participate in structured vocational education programs. This activity was to support a process of micro-economic reform of workplaces, aimed at improving the effectiveness of workers' skills to compete globally. My work took me to numerous workplaces. During these visits, I observed many work practices and talked with numerous workers about their work and how they learnt it. Through these interactions and observations, two issues became apparent that captured my interest. Many of these workers had not learnt their skills through vocational educational programs, as these programmes were unavailable. I constantly came across workers who had learnt their vocational practice through their work. Despite this, these workers seemed to be performing well and seemed none the worse for this kind of preparation. These reflections came together one day in a small sugar mill town in northern Queensland. The production of sugar is conducted through procedures where heat and pressure are used to extract and process the sugar. During the 'crush', the production workers monitor and make adjustments to the plant in order to maximise the sugar yield. I was drawn to consider how these workers had learnt these complex and demanding skills. I knew that there was little movement of workers between each town and mill. Essentially, the knowledge required to operate the mill resided in the 
community that surrounded the mill. From conversations, workers reported that learning processes that were part of everyday work practices had assisted these workers to understand and successfully operate the mill. This led to a questioning of my assumptions about how learning for vocations proceeds, as previously I had equated learning with teaching.

My educational background was a college-prepared technician, who had become a vocational educator through a teaching training college and had subsequently been involved in the professional development of teachers, supported by university studies. Hence, I had come to associate the kind of rich learning that these workers were demonstrating with teaching and participation in educational programmes. Yet, in the sugar mills and coalmines, the evidence challenged this assumption. Moreover, I reflected on my halting attempts to apply college-learnt knowledge to my first job in the clothing industry. The tasks were different to those I had been prepared for and had learnt about at college. The procedures used in the factory were unknown to me and the context in which the work was being conducted was quite remote from my previous (collegebased) experience. Much of the products of my college-based learning was not applicable to nor intelligible in the workplace. It was only years later, when I had experienced a number of different clothing manufacturing workplaces and practices, that the commonalities to the approaches to work tasks became apparent. I also recalled my first teaching role and reflecting at that time, that what I was teaching my students was different than what happened in the clothing workplaces. Some of this was the simple limitations and constraints of the classroom activities (e.g. it was not set out like a clothing workplace), some the equipment and resources we had to work with (e.g they were not those used in industry), but also the structuring of experiences were different than in those in the workplace. These earlier experiences may have led me to consider critically what I had learnt from the sugar mills and coal mines, rather than just dismissing these workers learning as being ad hoc, unstructured, peripheral.

This questioning and concerns led me to attempt to understand how and what individuals learn through their engagement in everyday activity in the workplace, the strengths and weaknesses of that learning process and its outcomes, and how they both might be improved. I commenced by adopting a cognitive psychological perspective, but soon moved to consider the social and cultural (e.g. Vygotskyian perspectives) and anthropological accounts (e.g. the work of Jean Lave), as much as the cognitive contributions to thinking, acting and learning (e.g. Billett 1996), the historical and cultural geneses of vocational knowledge (e.g. the work of Sylvia Scribner, Jacqueline Goodnow, Barabara Rogoff and Michael Cole) and the situational constitution of knowledge (i.e. Billett 1998) and expert performance (i.e. Billett 2001a). In parallel, my work extended to consider the unique socially-derived bases of individuals' thinking and acting (i.e. Billett 1997) and the reciprocal relations that constitute engaging in and learning through work (i.e. Billett 2001b, 2001c) which arose through evidence of idiosyncrasy in the outcomes of learning through the same workplace learning processes. Here, the work of Jaan Valsiner and his concepts of the co-construction of knowledge (1994) and associations between the cognitive and social experience have been highly influential (2000). This inquiry has already spanned a nine year period of attempts to understand more fully how and what workers learnt through everyday activities in the workplace and identify ways of improving that learning. The interest, independence and 
sense of a goal to understand and disseminate the findings from this line of inquiry energizes and directs my work.

\section{Direction 2 - Co-participation at work}

My recent work has focused on how individuals’ participation in workplaces influences how and what they learn. Drawing on the work of Rogoff $(1990,1995)$, Lave (1990, 1993), Wertsch (1985, 1998) and Scribner (1985, 1997), I came to hold learning and participation in social practice to be irreducible. However, participation is the product of social and political action, as well as individuals' subjectivities. Those whose participation is limited will be restricted in their opportunities to perform and learn effectively. From earlier studies, my own experience and the literature on work, opportunities to engage in workplace activities are not distributed evenly and are often contested. Moreover, how judgements about individuals' performance in workplaces are made also emerges as key bases for participation and, the bases for these judgements are not always objective. In my working life and research activities, I have witnessed how individuals, groups of individuals or cohorts of particular kinds are either included or excluded from participation in particular ways. This conclusion is well sustained in the literature on work and work practices. It also resonates with some of my personal experience. Opportunities to engage in work activities are not only distributed on objective appraisals of individual worth or value. The enactment of workplace cliques I have observed in public sector and university workplaces reflects the thuggish behaviour of schoolyard gangs. These affordances shape the ability to engage in activities and access guidance that can extend knowledge is central to learning and also the acknowledgement of performance.

I came to note, for instance, how individuals' performance is greeted in workplaces. Success for some is publicly and generously acknowledged. The success of others is dismissed as being low level, the product of luck or because they are workaholics (e.g. have no other life and are unworthy of recognition for their success). Equally, mistakes by some will be tolerated, even mused over, whereas a similar level of mistake (or even perception of incompetence by others) will be the basis for approbation, ridicule and a reason to exclude from participation. These bases can be immensely significant for the individuals concerned. This significance is no greater than when the work these individuals are engaged in is central to their key vocational or identity. That is the bases of their identity and subjectivity are directly challenged by attempts to exclude and devalue contributions. Here, again is the contested basis of subjectivity.

Conceptually, this is important, as any understanding of a view of learning, thinking and acting (knowing) premised on engagement with social partners and access to knowledgebuilding activities, that have their bases in social practice. Many current learning theories emphasise both these social contributions to individuals' knowing. However, psychological learning theories, and even those providing social and cultural accounts do not yet fully account for these relations. For instance, the concern within Vygotskian derived theories is largely about social reproduction. The key goals of learning from a sociocultural perspective, of inter-subjectivity and appropriation of cultural norms and values, smack of social determinism. Such social reproduction is clearly restrictive, as Dewey (1937) pointed out, but also implausible given the negotiated bases for the construction of identity, knowing and knowledge, that are well charted in the sociological 
theories of learning that Hodkinson and Bloomer prefer, and as referred to by Giddens (1984) as structuration.

This negotiated basis for participation has become a key element of my inquiry. Firstly, my interests have shifted and evolved to learning through participation, which inevitably leads to concerns about participatory practices. Secondly, the literature, my experience and my research in workplaces has identified this as a key premise for participation in and learning through work and in social practice more generally. I have witnessed how participatory practice play out in universities, government departments and private enterprises. So conceptually, this interest arises from a basis to understand participatory practice, learning and how opportunities for learning are distributed in workplaces that are highly contested. Participatory practices in my workplaces also reflect the contested subjectivities that Davies (2000) refers to as they are the source of a set of concerns that in different ways both constrain and empower my practice. One, and perhaps most the important, empowering quality is the capacity to consider, inquire and conceptualise these participatory practices. Certainly, there is more than coincidence between my research interest in this concept and events in my life history. These events shape my subjectivity and direct my interest in workplace participatory practice, and my evolving understanding of how learning or coming to know can best be understood.

So in similar ways, the interest that guides the direction of my inquiry into learning in workplaces and participatory work practices can be located in events in my life history. As a university researcher, I am probably more privileged and able than many others to exercise my agency in pursuing these key goals. However, I am only too aware of being subject to the demands of disciplines, the perils of interdisciplinary work and other factors that will seek to imperil this journey.

\section{Martin Bloomer's Story}

My story, like the proverbial football match, is one of two halves. The first, I share with most young people: I struggled with my identity formation. I was brought up at a time and place where authority was strongly vested in selected knowledge and cultural practices and I was given little opportunity to challenge them. Nor could I find an alternative suitably robust world view in which to place myself. I was an outsider, frustrated and confused. The second is marked by my introduction to symbolic interactionism, which, for me, represented a new development in social theory and the release of new opportunities for research practice. It also provided me with a platform from which I could challenge the authorities I objected to, having an application in my academic work and in the personal life that I was striving to come to terms with. My research career and my life history are therefore tightly intertwined, although it is only on reflection that I have come to recognise this.

Soon after the letter arrived informing my parents that I had passed the 11+ and had gained entry to a prestigious boys' grammar school, I became aware that the challenges which lay ahead would be greater than I had envisaged. My lifelong neighbourhood mates began to taunt me with the prospect of having to wear a boater to school, my father developed an instant enthusiasm for rugby union as my opportunities to play and watch my beloved soccer became eroded, and my mother became consumed by the idea that I would one day become a vicar. Even my father's drinking pal started to call me 'Old Chap.' 
Many young people in the UK at that time had change imposed upon them and many, like me, found it difficult to abandon their old ways and to integrate with the new. At primary school and in the street, all the boys had done everything together - except Raymond Glover - whose nose was always running; we sat together in class; we learned together through what, for the most part, we considered to be fairly agreeable and comprehensible challenges; we played together; we learned to smoke together and we learned to swear together. Everything had fitted together rather nicely and our adults protected us from most of life's irregularities and uncertainties. Now the security of these coherent cultural practices was about to be undermined. I was introduced to a world that showed little tolerance for the personal and cultural capital that I had accumulated.

I had to travel thirteen miles by three buses to my new school. Upon arrival, I was advised that I was in the 'A' stream and that I would receive two one-hour detentions for every late arrival and a further detention for being found not wearing full school uniform. I was to be known as 'Bloomer.' My new school fellows were a very different breed to likes of Raymond Glover: Gladstone-Fisher's father was a surgeon; Worsthrop’s was a headmaster; Simpkins' an accountant; and Levy's the owner of a huge car sales business. I quickly re-badged my foundry labourer dad as an engineer. My peers brought with them a new language and spoke confidently about things I'd never heard of, like prep schools, cruets and stocks and shares. We had new subjects to look forward to: French and Latin were temptingly mysterious while the study of physics and chemistry offered faint hopes that the excesses of the Beano (popular children's comic) might actually come true. None proved as exciting as I had hoped.

After a year, I slid from the 'A' stream to the 'B' stream, not because my attainments were among the lowest but because 'Bloomer might find it a more suitable challenge.' After a further year, I was demoted to the ' $C$ ' stream despite ending the year in the top half of the 'B' stream rank order: 'With improved behaviour and attitude, Bloomer might again aspire to the 'B' stream.' Bloomer didn't bother. Having had more detentions in the term than the school could staff, and been caned three times in the same day for separate misdemeanours, it was going to take more than a few aspirations to change my reputation.

My grammar school experience presented two contradictions. The first was between the virtues of 'high culture' and 'common culture'. I struggled to embrace both but succeeded only minimally. Linked to this, the second was between school knowledge as a basis of legitimacy and the 'folk authority' of my parents and neighbourhood. Both had a strong pull on me, yet, despite my keenness to do so, I was unable to resolve the tension between them. The abstracted, objective, universalised and 'academic' nature of school knowledge and the systematic and rigorously scrutinised processes through which it had been produced, presented a compelling case for accepting its authority - and I accepted it. On the other hand, the collective folk wisdom, generated from years of direct personal experience, made equally strong claims upon me. This exacerbated the problem of my identity formation and the development of my personal world view.

I was pleased to leave school at the earliest opportunity, a matter hastened by the fact I had had a number of entanglements with the law. Fortunately, I was able to walk off with a respectable clutch of O-levels (The standard 16+ qualification in English schools, at that time). After a period as an industrial labourer, I took up an engineering apprenticeship at 16 in the motor industry. This enabled my parents to give me a 'second 
chance', and it allowed me to re-build bridges with my neighbourhood mates. But things had changed. I had changed. I had come to embrace 'academic values' and the pursuit of intrinsically worthwhile knowledge. I had also come to reject hedonism and to experience anxieties about whether I would be sucked into the very world of drudgery that my parents had sought to spare me.

Having become a wage earner, I was able to spend most of my evenings playing with a rock band. From this, my interests soon expanded into blues. A selection of my neighbourhood mates had discovered George Formby and found that there was a living to be made from playing in public houses. Then somebody waved a Bob Dylan LP under my nose and mentioned that he'd heard his brother-in-law talk about folk clubs. Thus a neighbourhood splinter group of about five of us set off in pursuit of folk clubs and it was there that Dylan, Formby and the blues met English ballads, Irish Republicanism and the Communist party. Three of us became totally absorbed in this new culture and the folk club people showed a supportive interest in us. They encouraged us to perform and soon we were taking paid bookings at clubs and concerts across the country. Our repertoires assumed a more political purpose as we justified our renderings of English ballads on the grounds that they challenged standard imperialist history by articulating the seldom-told personal experiences of working men and women. But there was something else about our new-found friends: many were at university or had received university education and yet they treated us as equals. One even taught at my old school. I was given frequent encouragement to think about going to university. 'If we can do it, you can do it' was the common sentiment and this proved to be a major turning point in my life as I began to reposition myself in a newly-coherent world of values, beliefs and cultural practices vastly different to those of either my neighbourhood or my school. A few A-levels (the qualification above $O$ levels, that was the basis for university entry) and I'd be there!

My introduction to the folk club world helped me to overcome some of the difficulties I was experiencing in my identity formation. It offered me that coherent and robust world view that I had sought and I soon developed a clearer view of who I wanted to be in terms of my general outlook and values, my music, my politics and even my future career. However, I was still an outsider: my music was protest music; my politics was protest politics; my values were anti-capitalist; and the legitimacy of my new-found position was grounded outside both 'high culture' and the mainstream. It was not what my family, my neighbourhood or my school had prepared me for.

Eight years later, after three years' teaching experience and a masters' degree, I had begun to achieve some coherence in my approach to educational research. My theoretical allegiances were to interpretivism and structural Marxism. Once again I was an outsider, given the dominance of structural functionalism and quantitative research methods at the time. My commitment to interpretivism is to be understood, I think, in terms of its relationship with my life history on at least three distinct counts. Firstly, it promised an antidote to the conservatising impact of structural functionalism, the dominant psychologies and educational and social policies of the time. It offered an alternative to orthodox 'academic' practices and a potential source of legitimacy for my protests against mainstream, 'high culture' and establishment thinking. Secondly, in privileging subjective experience, it had the potential to legitimise some of the collective folk knowledge which had made such strong claims upon me. It was also consistent with my feelings about the importance of oral history and personal experience as captured in 
English ballads. Thirdly, and most importantly, it had the potential to provide 'academic authority' for understandings grounded outside mainstream, 'high culture' and establishment thinking. It assisted as much in achieving coherence and confidence in my personal identity formation as it did in marking out a possible research career.

My structural Marxism was partly rooted in the socialist convictions which had been a guiding force since my political education with the folk club people, and partly in the emerging neo-Marxist literature of the early seventies, by people such as Gramsci, Althusser, Bowles and Gintis and Bourdieu. Others (Sharp and Green and Willis, for example) were attempting to construct bridges between these two theoretical positions and I was much persuaded by them. While such works were frequently criticised on the grounds that they attempted to draw together perspectives whose underlying presuppositions were antithetical, I felt neither the need nor the desire to reject one or the other. As I wrote later in my $\mathrm{PhD}$ :

Structuralism presents no emphatic denial of the interactionist claim that man (sic.) responds to his own interpretation of reality. On the contrary, it takes it for granted. Similarly, interactionism does not deny the existence of external social forces in man's construction of his social reality; it merely focuses its attention on the construction rather than the forces. Put this way, the two perspectives ... are different only in the emphasis they attach to different aspects of the same problem (Bloomer, 1985, p 28).

My enduring commitment to such a view should not be seen in terms of the intrinsic justifications of the claim itself but in terms of how well it meshed with my personal needs at that time. While interpretivism assisted me in achieving coherence and confidence in my personal identity formation, that coherence and confidence was further enhanced as I blended it with structural Marxism. In this way, I was able to make my socialism compatible with my research career and to partly prepare myself both for the structure-agency arguments about to surface and for any criticisms about the onesidedness of interpretivism alone.

My PhD was influenced theoretically by Max Weber, and methodologically by Glaser and Strauss (1968). My supervisor, Ronald King, had deepened his own interests in Weber at around that time, and much of what King did resonated with my own interests and concerns. He had a profound influence upon the way I shaped my approach to research. Weber's theory of social action and his methodology of understanding (Verstehen) found a place at the heart of my thesis, and I found little difficulty in linking these ideas with Glaser and Strauss's approach to theory making.

Although structural Marxism was not prominent in my thesis, it has remained significant in my thinking. In my first reading of Bourdieu, for example in his discussion of 'intellectual field' and hierarchies of 'cultural legitimacy' (1971), it was the grounding of these concepts in the unequal distribution of power which seized my attention. I still maintain that Bourdieu's work is pre-eminently structural: 'While due emphasis is placed by Bourdieu upon subjective experience, it is a view of subjectivity as prescribed ultimately by objective probability. Objective conditions are the cornerstone of his theory' (Bloomer, 1997, p 142). But this does not mean that Bourdieu's work has no relevance for interpretivist theory and methodology. When Phil Hodkinson introduced 
me to Bourdieu's version of habitus, one of its main attractions was that it complemented interpretivist theory in so far as it, too, 'is premised upon the personal construction of meaning through processes of social interaction. It also uses disposition to link meaningmaking and action' (Bloomer, 2001, p 437). Another attraction was that it offered, 'a means of theorising a dialectic rather than dualistic relationship between agency and structure’ (p 437). But, despite its intrinsic merits, I would not have found Bourdieu's work so attractive had it not been compatible with and supported my prior personal commitments to interpretivism and socialism.

Throughout all this, phenomenology and, particularly, symbolic interactionism have been prominent in my approach to research and social theory. Berger and Luckmann (1971) was my first encounter with interpretivism, and I viewed it as revolutionary. The thinking of Mead, Becker and Goffman figured prominently in my attempts to create a coherent account of social interaction and meaning-making. More recently, symbolic interactionism was to provide a major theoretical cornerstone for my work with Phil Hodkinson on the notion of 'learning career' (Bloomer, 1997, 2001; Bloomer and Hodkinson, 2000). Everett Hughes' description of career as a subjective phenomenon or 'moving perspective' (1937, p 410) in which one interprets or attributes meaning to things around, and Goffman's discussion of 'the regular sequence of changes that career entails in the person's self and in his framework of imagery for judging self and others' (1968, p 119) resonated strongly with my own experiences. They reflected important attributes of the accounts of their lives and their experiences of learning provided by the young people who participated in the study carried out by Phil and myself in the late1990s. They also mirrored the experiences that I had had throughout my own troubled identity formation. Secondly, they offered a conceptualisation of processes of meaningmaking which, while centering individual constructions of reality, did not in my view discount the importance of external structures in those processes of construction.

An elementary structural Marxism, the centrality of personal constructions of reality, and the 'relational interdependency of agent and world' (Lave and Wenger, 1991, p 50) have been cornerstones of my understanding of social theory and research. They are also bound up in the processes of what I have called my identity formation. But for my particular experiences of childhood, of schooling, of the folk people and of my early adulthood, my values and understandings might have developed in other ways. It was my discomfort with the 'high culture' of my schooling and my absorption into the culture of practice of the folk people which inclined me to socialism. But it was the same schooling which propelled me to seek academic authority for my unfolding views. Oral history had figured in my own upbringing and the importance of personal subjective experience in making sense of the world was underscored for me as my participation in folk music increased. Thus, interpretivism and symbolic interactionism fell fairly naturally into place when I came across them. Finally, there was a sense in which the commitments I have described, to structural Marxism and to symbolic interactionism, were contradictory. However, I did not experience them as such. I regarded them as illuminating different facets of social phenomena, as a duality not a dualism. Symbolic interactionism, for me, did not obscure structuralism, as some would have it; as structures became manifest, so they became apparent in the social constructions of those exposed to them.

Reflecting upon what I have written, it is apparent that my research career was shaped partly through formal instruction, with certain individuals assuming particular 
importance in that. But that formal instruction was responsible for only a part of the researcher I was to become. There have been many transformations in my life and the impact of all the teaching I ever received was reciprocally linked with these: what I learned contributed to the transformations but the transformations whose origins often seemed to have lain elsewhere gave shape to what I learned. I have drawn upon a number of my life 'strands' here: my orientations to knowledge and learning, my music and my politics. I could have mentioned others, more profound, including the mysterious processes through which I became a husband, father and teacher. The point is that my becoming a researcher has been inextricably bound up in all other aspects of my becoming a person. It has been a learning career (Bloomer, 2001).

\section{Phil Hodkinson's story}

The roots of my research into learning fall into two strands, which complement and contradict each other. They are a belief in progressive teaching, and a sociologically enhanced awareness of deep inequalities in education.

\section{Strand 1: Progressive Teaching}

I became a secondary school teacher straight after graduating in geography, in 1968. Before that, I had attended a non-prestigious coeducational grammar school in Lancashire, as a boy from a lower middle class family where left-of-centre values were pervasive, and with many working class friends. Unlike Stephen and Martin, I found those schooldays relatively unproblematic. I entered my one year teacher training course with two passions: a love of geography as a subject, and an awareness of the inequalities produced by the 11+ system that was dominant in England at the time, and the streaming of pupils into rigid ability bands that often went with it.

This sense of inequality was fed by the experiences of a friend of mine at school. David lived on a council estate, the only son of a painter and decorator. At primary school, he was the star pupil. That primary school took the $11+$ seriously. 'Intelligence' was a subject on the timetable, where we practised and practised the sorts of test we would face in the 11+. By a quirk in the system, the older pupils were able to take the test a year earlier than the norm. We did this as practice for the following year. David was the only one who passed, at this premature age. Second time round, many of us passed, including myself. When we duly arrived at the grammar school, most of us were in the top stream, but David was in the second one. At the time this surprised me, but I thought no more about it. For five years, he stayed in the second stream and I stayed in the top. When we entered the sixth form I, like other ex-top stream pupils was made a full prefect. David, like those from lower streams, was made a sub-prefect. It was only whilst at university that I began to understand what had happened. I assume that David's 11+ score, earned a year too soon, had been too low to get him in the top stream. Had he failed first time around, he would have out-performed the rest of us, as he had always done before. Once in the second stream, his position became a self-fulfilling prophecy. His working class parents lacked what I would now term the cultural capital to challenge the school over his class allocation.

For this and wider political reasons, I was enthusiastic about the comprehensive school system that was expanding rapidly in England when I did my training. At interview, I was asked about teaching geography in mixed ability groups. I replied that it 
was desirable, but probably impossible to do effectively. The lecturer who interviewed me became my personal tutor, and was responsible for placing students for teaching practice. No doubt remembering my interview, he placed me in a strong geography department, in one of the few schools in the country where mixed ability grouping was prevalent. I did well there, and got my first professional post in another such school, where I worked as head of geography for 13 years. Like Stephen and Martin, I revelled in my self-image as a radical, contesting conventional school-teaching approaches, but as a member of a radical community, not a loner. Throughout this time, I retained an implicit model of teaching as transmission. I was the expert, passing on my superior knowledge of geography to pupils. The trick was to engage their interest in that process, and enable them to work at topics at their own levels.

I eventually left that predominantly rural, middle class school, and moved to a school with a relatively deprived catchment, and a working class, mixed race pupil population. I became retrospectively aware of the many subtle advantages I had possessed in my previous school, as had many of the pupils there. Whilst at this second school, I became centrally involved with a new prevocational course, the Certificate of Prevocational Education (CPVE). I went on an eight-week training course, which transformed my approach to education and teaching. On that course, I became a convert to progressive/democratic pedagogy, based on group work, project activity, negotiation, and student-centred learning, thus acquiring an alternative radical position. Suddenly, what was taught seemed less important than the processes of participatory learning and student autonomy. I moved schools again, but continued working in this progressive vocational mode, for about five years in all. At that point, through a series of pressures, coincidences and luck, I took a temporary lectureship in the School of Education at the University of Exeter, to introduce prevocational teaching approaches to the secondary training programmes. Now, the second strand in my life history became more dominant.

\section{Strand 2: A sociological perspective in educational inequalities}

Whilst in my first teaching job, I got a one year secondment to the Cambridge Institute of Education. There I studied two courses, one of which was the sociology of education. Here I was introduced to the founding fathers of sociology, and explored the significance of social class in structuring educational inequalities. I also attended an inspiring series of lectures by a young Anthony Giddens, who was based nearby. I became conscious of the significance of structure and agency debates, and his work appealed because he seemed able to accommodate both. As with Martin Bloomer, Berger and Luckmann (1971) was another strong influence.

In the other part of my course I encountered a range of philosophical writings about the curriculum and its purposes, including the deeply contrasting work of Hirst (1965) and Young (1971). I read Stenhouse (1975) as soon as it first appeared, unaware that it was to become an iconic text on progressive education and research. At the time, I reacted strongly to Hirst's contention that geography was not a 'form of knowledge' and drew upon Stenhouse and Young to attack the then dominant conventions for understanding knowledge and the curriculum.

Once I started in Exeter, I revisited this body of writing, to push-start my academic career. I became immediately aware that there was a developing philosophical and sociological literature that was critical of the prevocational education and progressive 
teaching that I believed in (Holt, 1987; Bailey, 1984; Avis, 1991). My sociological understanding meant that I could neither ignore nor easily dismiss these criticisms. However, a combination of personal belief and teaching experience meant that I felt many of the attacks were unfair. I started my academic career by exploring this tension. Just as I had studied to defend geography from Hirst, I now defended progressive vocationalism (Hodkinson, 1991a; 1994). I also did my first empirical research, evaluating the CPVE programme I had recently left behind. This research showed that broader political issues, central to the establishment of the course, undermined its teaching effectiveness (Hodkinson, 1991b). I was becoming sub-consciously aware that social forces were more significant than pedagogy, in determining learner success.

I followed this with my first major funded research project. Myself, Andrew Sparkes and Heather Hodkinson followed a small group of trainees into and through a new youth training programme. We interviewed the young people several times, and also other 'stakeholders' whom they worked with: parents, teachers, careers advisers, trainers and employers. As that research developed, we were searching for theoretical approaches to help make sense of our work. A central focus became the ways in which our young trainees made decisions about job and training courses, which bore little relation either to the assumptions of the scheme they were following or to the existing literature on such career decision making. Partly because of Andrew's prior reading (he was the most experienced academic of us, and the most thoroughly grounded sociologist), we began by drawing upon phenomenology and symbolic interactionism: Schutz and Strauss in particular. However, we were searching for a perspective that balanced their predominantly agency-driven approaches with a more structural dimension. Predictably, given my past, I went first to Giddens, especially his book on modernity and self-identity (Giddens, 1991). Andrew suggested that I also read some Bourdieu, and I did so, staring with his conversation with Wacquant (Bourdieu and Wacquant, 1992).

As our thinking developed, and as we further analysed and wrote about our data, some of Bourdieu's ideas became increasingly dominant. Possibly because he did not engage directly with complex social interrelationships, Giddens seemed to have less heuristic purchase. The relational links between Bourdieu's concepts of habitus, position, field and cultural capital proved a valuable means of making sense of our accumulating data. Some Strauss remained, and we coined the concept 'horizons for action', which I suspect derives loosely from Schutz. These were amalgamated into a self-proclaimed 'sociological theory of career decision making' (Hodkinson and Sparkes, 1997).

After this, Martin Bloomer and I began to work together, on a project following 50 young people through Further Education. This time, the sample of young people was so large that we only interviewed a small number of significant others. In the previous study, the stakeholder interviews had been built in at the cost of reducing the sample of trainees to twelve. This difference in sampling may have meant that, at least early on in the data collection, issues of structural inequality were less apparent, and of student belief and agency more foregrounded. However, our interview schedules were constructed to elicit information from the students about their home backgrounds, families and friends, where issues of class, gender and ethnicity became apparent, when we searched.

As the research advanced, Martin and I agreed about most things. This was helped because we both approached learning from predominantly interpretivist positions. It was obvious to us that the learning of our sample students could only be understood through 
their life histories and their wider lives. It was also apparent that those lives were very unequal, in ways related to social class, gender and ethnicity. However because we were charting the development of what we termed their learning careers in real time over four years, the inherent unpredictability of those careers was also clear. Frequently, individual stories took an unexpected turn, in ways that were consistent with my earlier theorising with Sparkes, about career decision making. Having already used Bourdieu, I drew on his theorising once more, when looking at this data. But Martin initially did not. There are subtle differences between the papers where he was first author, and those where I was. In our final paper, he wrote the first half, from a predominantly symbolic interactionist perspective, and I wrote the second, focussing on cultural capital (Bloomer and Hodkinson, 2002). However, I feel that we missed out a dimension in our work, because our sampling meant that the complex interactions within what Bourdieu might have termed the field of further education, what Billett describes above as interdependencies, were never examined, except through the perceptions of the students.

\section{The further development of my research career}

As both research projects progressed, my academic career was subtly changing. Geography is now a memory, and my belief in student-centred learning has waned. My research increasingly showed that learning depends upon so much more than the pedagogy of the teacher. My own teaching has reverted to a more mixed style, involving didactic lectures and tutor-led seminar work, as well as student activities.

My views on research have evolved into a hermeneutical, intepretivist position, where my open espousal of relativism (Smith and Hodkinson, 2002) has provided my third radical identity, again within a circle of valued colleagues. This ties back to my earlier reading of Giddens (1976), Berger and Luckmann (1971) and Stenhouse (1975). It was reinvigorated through working with Andrew Sparkes, who is himself at the forefront of writing about interpretative research. He introduced me to another expert, John K. Smith, who remains a major influence as well as a friend and who, in turn, introduced me to the writings of Gadamer. In Gadamer (1979), I found resonances with my previous use of Bourdieu. For Gadamer describes knowledge accumulation (read here either learning or research) as the fusing of horizons, within effective history. He argues, like Bourdieu, for the primacy of position: that we start from a standpoint and that we can only learn/research from that standpoint. From that standpoint, what we can learn/research is constrained and enabled by the horizons before us. New knowledge is constructed by placing our prejudices at risk, and fusing our understandings with those of others. All this is part of an evolving but contingent tradition, which we can neither step outside of nor control. Within that tradition our standpoints and horizons can move and shift, but the past is an inescapable yet non-deterministic influence on the present. My discovery of Gadamer reinforced the attractions of a Bourdieuian analysis of learning careers. Such thinking has become part of who I am - a part that can be no more erased or ignored than can my roots in the potentially progressive purposes of education and learning, or my deep-seated concern with social and cultural inequalities in education and society. Indeed, its trace can be seen in the ways that I have constructed this story.

I remain partly unsure about why Bourdieu has become so important to me. My use of his work has helped partially resolve the tensions in my own past. Yet I have never become an expert on his thinking, and remain only patchily familiar with his writing. 
Perhaps the role of acolyte would be at odds with my consistent searches for leading edge, rebel identities. I continue to find aspects of Bourdieu's thinking heuristically valuable, in making sense of complex situations. I can normally find strong logical arguments about the superiority of my position, drawing upon Bourdieu and Gadamer, to those of others. The trouble is, these others can do the same, with respect to the superiority of their position over mine. Often, my arguments are convincing to me but less so to others, and vice versa. So there has to be something more. I suspect there is a part of my allegiance to Bourdieu that is emotional (a view that is consistent with his theorising of habitus as being embodied and predominantly tacit). What would have happened, I wonder, if, instead of reading his work, I had focussed on someone else: Beck perhaps, or Vygotsky? Would such work have proved equally attractive, providing a different resolution to my belief conflicts?

Bourdieu, like Gadamer and several other thinkers, has become part of my identity as a researcher and writer. He is part of my habitus, and part of the standpoint from which my academic life continues to develop. But, like the learning careers of the students Bloomer and I studied, the future of my work remains partly unpredictable. Will Bourdieu decline in significance as my work moves in different directions? Will his thinking be relegated to the past, in the way my original love of geography has been? Early signs are that it will persist. In a recent research project, Heather Hodkinson and I studied the ways in which secondary school teachers learn at work. Heather has been my most constant research companion, as well as wife and friend. When we work together, she tends to concentrate more on the data, whilst I fly off into broad theorising. She has influenced my theoretical thinking through continually forcing me back to the detail of the data, and has acted as a fairly constant reinforcement of the position I have come to adopt, perhaps especially the hermenutical relativism. Our on-going partnership probably makes it more unlikely that I would suddenly branch off in a radically different direction. In making sense of our new data, we drew extensively on Lave and Wenger's (1991) work on communities of practice. I was immediately struck by some similarities in between their theoretical stance and that of Bourdieu. Heather and I have developed this work to incorporate individual worker/learner dispositions (Hodkinson and Hodkinson, 2003), in ways that parallel Billett's (2001c) recent work on affordances and interdependencies at work. In taking this approach further, and trying to incorporate power differentials and more structural dimensions of learning, we have turned explicitly to Bourdieu again (Hodkinson and Hodkinson, in press).

\section{Making Sense of These Stories}

In analysing what these stories mean in relation to our questions (Why do we see similar issues through different theoretical lenses? What are the implications of this, for understanding learning, and the nature of theory in the construction of research?), each of us can construct a different explanation. As Martin Bloomer died before he had time to work on this part of the paper, we present those of Billett and Hodkinson. Partly at Hodkinson's instigation (we cannot even completely agree about this!), we have resisted attempting to merge the two accounts. This is because each of them is as much a further reflection of our different theoretical positions, as it is a rational identification of the meanings located in the three stories. 


\section{Billett's Account: Intentionality and life directions}

The idea that the intentionality in individuals' life direction is shaped by contested and negotiated subjectivities, that are in turn a product of life histories or ontogenies and which in turn shape intentionality, is consistent with a cache of propositions about human development. These propositions are associated with the merit of this intentionality and its association with human development: that is change in humans directed towards desired goals. In terms of merit, and from a philosophic perspective, Dewey (1916) proposes that life directions or vocations are central to individuals' well-being and sense of identity. Hence, aligning these life directions to individuals' interests represents important personal goals. Taking the broader notion of vocation he argued that, whether through paid or non-paid activities, we seek to realise goals associated with our life direction. Failure to achieve these goals or the ability to pursue them comes at a cost.

"To find out what one is fitted to do and to secure an opportunity to do it is the key to happiness. Nothing is more tragic than failure to discover one's true business in life or to find that one has drifted or been forced by circumstances into an uncongenial calling.” (Dewey 1916 p.308)

From this perspective, the merit of the pursuit of a line of inquiry that is aligned to the researchers' evolving interest, life goals and well being is endorsed. The kinds of inquiry that researchers are engaged in should be aligned to their interests and not only reflect the interests of others (e.g. sponsors of research, supervisors). However, the question being addressed in this paper goes beyond the merit to understand what factors guide or drive the intentionality that forms and prosecutes intellectual inquiry. Here, the concern is to understand and illuminate the relations between the focus of researchers' inquiry and their life history.

Within psychological thought, there is a long tradition emphasising the directed engagement of individuals in their thinking and acting, and consequently with their psychological development (i.e. cognitive, emotional and personality). Meade (1934) proposed engagement rather than passivity in human encounters with the social world. He conceptualised human cognition constituting an ongoing stream of conscious engagement with the social world, which was interpretatively and mutually constructed. Piaget (1966) identifies the centrality of the reciprocity between the individual and the social world in his notion of equilibrium, which included intentionality in evaluating and responding to stimuli located in the social and cultural environment. He proposed individuals act only if they experience a need; that is if the equilibrium between the environment and the organism is momentarily upset, and action tends to re-establish the equilibrium (Piaget 1966). Disequilibrium, therefore, is a product of an unsatisfactory appraisal of an encounter with the social world. Extending the basis for intentionality to include values that are central to the individuals well being and interest, Claprede (1910 cited in Piaget 1966) proposes that 'feelings appoint a goal for behaviour', while intelligence merely provides the means ("the technique”). He holds that there exists an awareness of ends as well as means, and this continually modifies (re-adapts is the term he used) the goals of actions. In doing so, he places what is now described as individuals' subjectivities at the centre of human intentionality, as these feelings or interests regulate 
internal energies, or as Piaget (1966) proposes controls the exchange of energies with the external environment.

Recent and revisited psychological accounts emphasise personal epistemologies arising from social circumstances and in circumstances, and have re-invigorated an interest in the reciprocity between the individual and the social world (e.g see Ratner 2000). For instance, appropriation as proposed by Leontoyev (1981), Rogoff (1995) and Wertsch (1998) emphasise reciprocity and discrimination in the construction of individuals' ways of knowing, (thinking and acting). Valsiner and van de Veer (2000) capture this as the intersection between the psychological (individual) and social experience that constitutes co-constructive processes of human development. In applying these concerns to the question being discussed in this paper it seems that the relations between ontogeny (personal history) and history is contested and negotiated. The development of individuals is through exercising discretion and agency in what they think, how they consider, organise and deploy what they know. This extends to and is shaped by the life direction they seek to pursue. This is not to posit the individual in opposition to the social but to view ontogenies or personal histories as being socially shaped by in multiple and probably unique ways and through interactions with different sociogeneses or social sources, agentically. So perhaps understanding the biography of researchers and its relationship to their inquiry will allow consideration of this more general point.

\section{Hodkinson's Account: Research careers as developing habitus}

Our respective stories demonstrate that we each approached our research careers from complex positions, rooted in our past lives - particularly our early lives.

Throughout our lives, we developed dispositions - to life, to education and, eventually, to research, as part of our personal habitus. What is striking in all three stories, is the way in which our wider social background, our early experiences of education, and deep personal convictions about injustice, influence our thinking to this day. Though we cannot fully bottom it out, the early latching on to a particular theoretical or disciplinary perspective also contributed to who we are, and framed our developing research interests. Thus, Billett moved towards socio-cultural explanations from a cognitive psychological foundation. In contrast, Bloomer and Hodkinson developed early roots in interpretive sociology, each, in different ways, searching for a resolution to structure and agency debates. These and other partly serendipitous and partly intentional experiences and events in our lives, contributed to the continuing (re)construction of our habituses and identities. At the same time, they introduced new dimensions to our positions in the world and the academy, as Bloomer became a symbolic interactionist with Marxist tendencies, Hodkinson a hermenuetical but also Bourdieuian sociologist, and Billett a social psychologist.

At each stage in this continuing process, the combination of our positions and dispositions constructed our horizons for action, with regard to research and writing. As Hodkinson and Sparkes (1997) make clear, such horizons are partly external and objective, and partly internal and subjective. It is not just external circumstances that determine horizons, but also our subjective perceptions of ourselves and of those externalities. The horizons both enable and constrain our opportunities for thinking, researching and writing, in ways that we are only partly aware of. Within these horizons, 
we take action and make 'choices', though some of these choices are serendipitous, tacit or even passive, rather than deliberative and active, although these changes may have been in response to what we have unintentionally experienced. They are pragmatically rational, rather than either irrational or purely rational (Hodkinson and Sparkes, 1997). Those actions and choices are informed by and themselves inform our developing habitus and identity and, therefore, further shape our future horizons. Those horizons also continue to be shaped by factors external to us, which are not always acknowledged in the earlier stories: such as the published literature that we can get access to, the research projects we can get funding for, our interactions with others, at work and elsewhere, some of whom are more powerful than we are (see also Hodkinson, 2000, in press), and the historical, political, economic and social climate in which we live and research.

The deep-seated values and interests that make up the habitus, and our past history from which they derive, cannot be somehow bracketed off. In that sense, our work is not, and cannot be, purely objective. However, as our lives progress, the dispositions that make up the habitus can and do change, and our stories present examples of such change. Just as Bloomer and I claimed for learning careers (Bloomer and Hodkinson, 2000) evolving research careers are made up of partly personal and idiosyncratic dynamics between continuity and change. Occasionally, change can be dramatic, though it is interesting that such drama is clearer in relation to our earlier, nonresearch lives, as presented in the above stories. Perhaps the deliberative elements of research thinking and writing make dramatic changes of stance, like the one I experienced in teaching, more unlikely. Once we had become professional researchers, all three stories resemble gradual progression or evolution. However, that progression is partly contingent, and not crudely goal-directed. None of us knew where we were moving to, in the early stages of our journeys. We were growing onwards and outwards, rather than growing towards something.

Within these evolving stories, at least for Bloomer and myself, engagement with significant others has been very important. There is an element of serendipity about this: Bloomer's close association with King as a doctoral supervisor, my latching on to Sparkes as a research colleague. But both examples were more than just accidents. Bloomer and King, and Hodkinson and Sparkes progressively developed mutual affinities towards research, that each member of the pair was comfortable with. Some other possible pairings would not have developed in this way, or been so influential. Such relationships, like that between Bloomer and myself, were based upon more than intellectual affinity. Bloomer and I, and Sparkes and I, were friends who shared broadly similar political values. There were emotional and values-impregnated ties that reinforced and were reinforced by the intellectual ones. More recently I have been working closely with a valued female colleague, Helen Colley. Her radical feminism is shared by other academics in the department in Leeds that I joined about four years ago. These professional relationships are beginning to shift my thinking again. However, Helen is as keen on Bourdieu as I am, so these new shifts are likely to further reinforce my predilections for his work.

So, researchers, like other learners, are whole people, not just rational thinkers. Their pragmatic rationality is merely part of what Beckett and Hager (2002) term their embodied judgement making. 


\section{Conclusion}

To conclude, through different, though is some ways similar routes, each of us has examined and considered the relations between human agency as ontogeny or ontology, with its overlay of subjectivity, and culture. We have not exercised our preferences arbitrarily. Our theoretical preferences have evolved through agentically engaging with socially structured experiences. These relations are uneasy, dynamic and contested. The rub between these agencies and culture show through in each of the stories, sketched out above. What is significant is how different routes have led through decade long processes of active reflection and critical scrutiny to similar concerns, although distinguished by differences in disciplines and perspectives, that will not go away.

But how different are our explanations of this situation, couched as they are, in different language, and drawing upon different bodies of theorising? Can they be synthesised into one, unified account? To the extent that they are different, there is no entirely rational way for us, or for our readers, to objectively determine which of our accounts of learning or of the research processes we have gone through, is the more correct, or even the more generally useful. We can continue to argue amongst ourselves, about the relative merits of sociology or social psychology, or between Bourdieu, symbolic interactionism and Vygotsky. Billett and Hodkinson may come closer together, as they increasingly recognise and incorporate the benefits of the other's position and arguments, and we could have used the writing of this paper as an opportunity to do that, by striving to integrate our reflections on the stories. However, differences will almost certainly remain.

Readers may replicate our debates or, much more likely, substitute their own, agreeing or disagreeing with one or all of us, depending upon their readerly positions and dispositions. Rationality and logical argument will, or certainly should, form a central and significant part of such a debate, but it is never enough. We are what we write, we are what we read and we are what we make of what we read. Researching and theorising, like other forms of learning, are historically, socially and personally positioned and constructed.

\section{References}

Avis, J. (1991) The strange fate of progressive education. In Education Group II Education Limited: Schooling and Training and the New Right Since 1979, (London, Unwin Hyman).

Bailey, C. (1984) From the Present and the Particular: a Theory of Liberal Education (London, Routledge and Keegan Paul).

Beckett, D. and Hager, P. (2002) Life, Work and Learning: practice in postmodernity (London: Routledge).

Berger, P.L. and Luckmann, T. (1971) The Social Construction of Reality, (Harmondsworth: Penguin).

Billett S (1996) Situated learning: Bridging sociocultural and cognitive theorising. Learning and Instruction, 6 (3) 263-280.

Billett, S. (1997). Dispositions, vocational knowledge and development: sources and consequences. Australian and New Zealand Journal of Vocational Education Research, 5 (1), 1-26. 
Billett S R. (1998) Situation, Social systems and learning. Journal of Education and Work 11 (3) 255-274.

Billett S (2001a) Knowing in practice: Re-conceptualising vocational expertise Learning and Instruction 11 (6) 431-452.

Billett S (2001b) Coparticipation at work: Affordance and engagement. In T Fenwick (ed.) Sociocultural perspectives on learning through work. New Directions in Adult and Continuing Education Volume 92. (San Francisco: Jossey Bass/Wiley).

Billett S (2001c) Learning throughout working life: Interdependencies at work. Studies in Continuing Education 23 (1) pp.19-35.

Bloomer, J.M. (1985) Pastoral Care in a Comprehensive School. Unpublished PhD thesis, School of Education, University of Exeter.

Bloomer, M. (1997) Curriculum Making in Post-16 Education: the social conditions of studentship (London, Routledge).

Bloomer, M. (2001) Young Lives, Learning and Transformation: some theoretical considerations, Oxford Review of Education, 27 (3) 429-449.

Bloomer, M. and Hodkinson, P. (2000) The Complexity and Unpredictability of Young People's Learning Careers, Education and Training, 42 (2) 68-74.

Bloomer, M. \& Hodkinson, P. (2002) Learning Careers and Cultural Capital: adding a social and longitudinal dimension to our understanding of learning, in R. Nata (ed) Progress in Education, volume 5 (Hauppauge, NY: Nova Science).

Bourdieu, P. (1971) 'Intellectual Field and Creative Project' in Young, M.F.D. (ed.) Knowledge and Control (London: Collier-Macmillan), pp 189-207.

Bourdieu, P. and Wacquant, L.J.D. (1992) An Invitation to Reflexive Sociology (Cambridge, Polity Press).

Davies, B (2000) A Body of Writing 1990-1999. (Walnut Creek CA, Altamira Press).

Dewey J (1916) Democracy and Education. (New York: The Free Press).

Dewey, J. 1937 Experience and Education. (New York: Collier).

Gadamer, H-G. (1979) Truth and Method 2nd. ed. (London: Sheed and Ward).

Giddens, A. (1976) New Rules of Sociological Method: a positive critique of interpretive sociologies (London, Hutchinson).

Giddens. A, (1984) The constitution of society: outline of the theory of structuration, (Polity Press, Berkeley: University of California Press).

Giddens, A. (1991) Modernity and Self-Identity: self and society in the late modern age (Cambridge, Polity Press).

Glaser, B. and Strauss, A. (1967) The Discovery of Grounded Theory (London: Weidenfield and Nicholson).

Goffman, E. (1968) Asylums: essays on the social situation of metal patients and other inmates (Harmondsworth, Pelican).

Hirst, P. H. (1965) 'Liberal education and the nature of knowledge, in R. D. Archambault (Ed) Philosophical Analysis and Education (London: Routledge and Keegan Paul).

Hodkinson, P. (1991a) Liberal Education and the New Vocationalism: a progressive partnership? Oxford Review of Education, 17 (1): 73-88.

Hodkinson, P. (1991b) Contexts and Innovation: a case study of the use of CPVE with Alevel students. Educational Studies, 17, 2, 191 - 203. 
Hodkinson, P. (1994) Empowerment as an entitlement in the post-16 curriculum Journal of Curriculum Studies, 26 (5) 491-508.

Hodkinson, P. (2000) Standpoints, Power and Conflicts in Contemporary Debates about Educational Research: An interpretation of repeated rejections, Auto/Biography, VIII (1 \& 2) 3 - 12.

Hodkinson, P. (In Press) Research as a form of work: expertise, community and methodological objectivity, British Educational Research Journal.

Hodkinson, P. \& Hodkinson, H. (2003) Individuals, Communities of Practice and the Policy Context: school-teachers learning in their workplace, Studies in Continuing Education, 25 (1) 3-21.

Hodkinson, P. \& Hodkinson H. (In Press) The Significance of Individuals’ Dispositions in Workplace Learning: a case study of two teachers. Journal of Education and Work.

Hodkinson, P. and Sparkes, A.C. (1997) Careership: a sociological theory of career decision making, British Journal of Sociology of Education, 18 (1) 29-44.

Holt, M. (ed) (1987) Skills and Vocationalism: the easy answer (Milton Keynes, Open University Press).

Hughes, E.C. (1937) Institutional Office in the Person, American Journal of Sociology, 43, 3, pp. 404-413.

Lave, J. (1990). The culture of acquisition and the practice of understanding. In J. W. Stigler, R. A. Shweder \& G. Herdt (eds). Cultural psychology (pp. 259-86). (Cambridge. U.K: Cambridge University Press).

Lave, J. (1993). The practice of learning. In S. Chaiklin \& J. Lave (eds). Understanding practice: Perspectives on activity and context (pp. 3-32). (Cambridge, UK: Cambridge University Press).

Lave, J. and Wenger, E. (1991) Situated Learning, (Cambridge, UK: Cambridge University Press).

Leonteyev, A.N. (1981). Problems of the development of the mind. (Moscow: Progress Publishers).

Meade, G.H. (1934) Mind, Self \& Society: Works of George Herbert Meade, Volume 1, (Chicago: University of Chicago Press).

Piaget J 1966 Psychology of intelligence. Littlefield, Adam and co. Totowa, NJ

Ratner, C. (2000). Agency and culture. Journal for the Theory of Social Behavior 30(413-434).

Rogoff, B. (1990) Apprenticeship in Thinking - Cognitive Development in Social Context. (Oxford: Oxford University Press).

Rogoff, B. (1995) Observing sociocultural activities on three planes: Participatory appropriation, guided appropriation and apprenticeship, In J.V. Wertsch, P. Del Rio \& A. Alverez (eds), Sociocultural Studies of the Mind, (Cambridge, UK: Cambridge University Press, Cambridge).

Scribner, S. (1985) Vygostky's use of history. In J.V. Wertsch (ed), Culture, Communication and Cognition: Vygotskian Perspectives. Cambridge University Press).

Scribner, S. (1997 [1990]) A sociocultural approach to the study of mind. In E. Tobah, R.J. Falmagne, M.B. Parlee, L.M. Martin \& A.S. Kapelman (eds), Mind and 
Social Practice: Selected Writings of Sylvia Scribner. (Cambridge: Cambridge University Press) pp. 266-80.

Smith, J.K. and Hodkinson, P. (2002) Fussing about the Nature of Educational Research: the Neorealists versus the Relativists. A Review Essay. British Educational Research Journal, 28 (2) 291-296.

Sparkes, A.C. (2002) Telling Tales in Sport and Physical Activity: A qualitative journey (Leeds: Human Kinetics).

Stenhouse, L. (1975) An Introduction to Curriculum Research and Development (London, Heinemann).

Valsiner J \& van der Veer R 2000 The Social Mind: The construction of an idea. (Cambridge, UK: Cambridge University Press).

Valsiner, J. (1994) Bi-directional cultural transmission and constructive sociogenesis. In W. de Graaf \& R. Maier (eds), Sociogenesis Re-examined. Springer, New York, pp. $101-34$.

Wertsch, J.V. (ed) (1985) Culture, Communication and Cognition: Vygotskian Perspectives. Cambridge University Press. Wertsch, J.V. (1998) Mind as Action. (Oxford: Oxford University Press).

Young, M.F.D. (1971) (ed) Knowledge and Control: New directions for the Sociology of Education (London, Collier-Macmillan). 